\title{
Soap Production from Agricultural Residues - a Comparative Study
}

\author{
L. E Yahaya*, A. A Ajao, C. O Jayeola, R. O Igbinadolor, F. C Mokwunye \\ End-Use Research Division, Cocoa Research Institute of Nigeria, Ibadan, Nigeria
}

\begin{abstract}
Four agricultural by-products namely Cocoa pod husk (CPH), Kola pod husk (KPH), Plantain peel (PP), and Orange peel (OP) were examined for their potential as alternative source of potash for soap production. These materials were ashed and the samples were subjected to hot aqueous extraction. Extracts from the ashed samples were characterized of their inorganic elements viz calcium, sodium, potassium and magnesium. Results indicated that these samples contains appreciable amount of potassium, a precursor material for soap production with $\mathrm{CPH}$ giving the highest value (41\%). The percentage amount of the potash is of the order $\mathrm{CPH}>\mathrm{KPH}>\mathrm{PPA}>\mathrm{OPA}$.

Liquid soaps were thus prepared from the extracts of CPA, KPH, PPA and OPA. Physical and chemical characteristics of the resulting soap products were carried out. The overall quality of the products compared well with that of the standard with exception of OP which showed little variations.

Indications therefore abounds that these agricultural residues are suitable material or alternatives for convectional alkalis for soap production.
\end{abstract}

Keywords Agricultural Residues, Soaps, Alkalis, Chemical Characteristics

\section{Introduction}

There has been high demand for surface active agents like soap over the years. This could be probably as a result of its usage virtually in all household affairs. According to McCutheon (1974), soap which is alkali salts of long chain carboxylic acids belongs to the class of anionic surfactant.

Surfactants have been defined as an organic compound which alters the conditions prevailing at the boundaries between different phases in a system e.g between water and oil in the formation of emulsion or between water and air in the case of foams. (McCutheon, 1974).These compounds (surfactants) consist of two parts: a hydrophilic portion which include a long hydrocarbon chain and a hydrophobic portion which renders the compound sufficiently soluble or dispersible in water or other polar solvent. The combined hydrophilic and hydrophobic moieties of the compound makes it active and thus able to concentrate at the interface between surfactant solution and another phase such as air, soil and textile or other substrate to be cleaned. (Shreves, 1967). Soap forms the largest group of the detergents that are in common use today as they constitute about $95 \%$ of all the detergents(Wilkinson,1974). A soap molecule consists of long hydrocarbon chain with a carboxylic acid group on one end which is ionic bonded to a metal ion, usually a

* Corresponding author:

eugeneyah@yahoo.co.uk (L. E Yahaya)

Published online at http://journal.sapub.org/chemistry

Copyright (C) 2012 Scientific \& Academic Publishing. All Rights Reserved sodium or potassium. The hydrocarbon end is non polar and is soluble in non polar substances such as fats and oils, and the ionic end (the salt of a carboxylic acid) is soluble in water (structure represented in scheme 1).

Saponification which is the basic reaction leading to the formation of soaps employs the use of fatty acids and alkalis such as potassium and sodium hydroxide. The pressure on the use of these chemicals for soap production has resulted in its exorbitant price. Efforts have therefore been geared towards sourcing for alternatives. Majority of agricultural materials are embedded with these alkalis which can be used if properly harnessed. Some of these materials include cocoa pod husk (CPH), kola pod husk $(\mathrm{KPH})$, orange peel $(\mathrm{OP})$, and plantain peel (PP).The availability of these materials has also rekindled the interest of this study; for example, it has been estimated that that Nigeria produces about 185,000 metric tones of cocoa (Theobroma cacao) per annum (CAN, 2006). The implication of this is that heaps of the pod husks abound as wastes in the plantation which constitute menace to plantation crops. Plantain (Plantago $s p$.) is also a common staple food in Africa and its production figure is enormous. The peels are often disposed as wastes in streets. Orange, (Citrus sinensis) is a major citrus cultivated in Nigeria especially in the south western part of the country. All these by-products are often regarded as wastes.

In our effort to add value to these plantation crops, the seemingly waste products from these crops were tapped by extracting potash and using the potash for soap production.

This paper thus report a comparative study of soap 
produced from the by-products of these agricultural residues.

$$
\begin{gathered}
\mathrm{CH}_{3}-\mathrm{CH}_{2}-\mathrm{CH}_{2}-\mathrm{CH}_{2}\left(\mathrm{CH}_{2}\right)_{9} \mathrm{CH}_{2}-\mathrm{C} \mathrm{O} \mathrm{O}-\mathrm{Na}^{+} \\
\text {ionic end }
\end{gathered}
$$

(Soluble in nonpolar substances) (Soluble in water)

Scheme 1. Schematic representation of a typical soap.

\section{Materials and Methods}

\subsection{Materials}

Materials used for this experiment included diethyl ether, hydrochloric acid, acetone, ethanol and potassium hydroxide. Also used were palm kernel oil, flame photometer, kiln furnace, $\mathrm{pH}$ meter ( kent EK 7020). etc.

\subsection{Preparation of Potash}

Dried cocoa pod husk $(\mathrm{CPH})$ and kola pod husk $(\mathrm{KPH})$ were obtained from the Cocoa Research Institute of Nigeria, Ibadan, while plantain peel (PP) and orange peel (OP) were obtained from the open market. $\mathrm{CPH}, \mathrm{KPH}, \mathrm{OP}$ and $\mathrm{PP}$ were subjected to the process of ashing. In this case, large quantity of each sample was introduced into an incinerator and heated at an elevated temperature of about $450^{\circ} \mathrm{C}$ for one hour. Known weights of the ashed samples were boiled for an hour. This was followed by filtration. The filtrate which contains the mineral elements were taken and assayed for calcium, magnesium, potassium and sodium using flame photometer according to AOAC methods (AOAC, 1990).

\subsection{Liquid Soap Preparation}

Preparations of liquid soaps from these agricultural wastes were carried out according to standard methods (Kirk-Othmer, 1967; Chaco et al, 1993; and Yahaya et al., 2002). Each extract was concentrated to correspond to 38 Baume, a value equivalent to alkali concentration for convectional soaps. For each sample, one part of palm kernel oil was reacted with two parts of the extract with constant agitation until a semi-solid mass was obtained. This was allowed to stand for 24 hours after which they were dissolved liquid of desired viscosity.

\subsection{Evaluation of the Detergency of the Soaps}

The performance characteristics of the resulting liquid soaps were determined by carrying out the lather test according to prescribed method (Chaco, et al 1993). In a typical experiment, $0.02 \mathrm{~kg}$ each of the soap samples was dissolved in $0.1 \mathrm{dm}^{3}$ in boiling water. A similar solution of synthetic detergent supplied was also prepared. Drops of oils were introduced into the test tubes. $0.1 \mathrm{dm} 3$ of distill water to one, $0.1 \mathrm{dm}^{3}$ of prepared soap solutions to others and $0.1 \mathrm{dm}^{3}$ of detergent solution to the third test tubes. These tubes were agitated vigorously while in closed state. The formations of lather were examined and compared. The emulsifying ability, i.e., how well the oil was converted to the colloidal state was noted. The $\mathrm{pH}$ of the resulting liquid soaps was measured using a $\mathrm{pH}$ meter.

\subsection{Chemical Characteristics of the Liquid Soaps}

The chemical characteristics, hence the quality of the resulting soaps were evaluated as follows; free fatty acid was determined titrimetrically, unsaponified neutral fat by saponification and then extraction, free alkali and neutral fat by standard methods (AOCS, 1965; AOAC, 1990; ASTM, 1971).

\section{Results and Discussions}

\subsection{Mineral Elements from Agricultural Residues}

Table 1. Mineral element from agricultural residues.

\begin{tabular}{|c|c|c|c|c|}
\hline Elements & \multicolumn{4}{|c|}{ Amount (\%) ${ }^{\mathrm{a}}$} \\
\hline & $\mathrm{CPH}$ & $\mathrm{KPH}$ & OP & PP \\
\hline Calcium & 0.16 & 1.30 & 2.8 & 6.89 \\
\hline Magnesium & 0.06 & 5.07 & 1.64 & 3.35 \\
\hline Potassium & 41.00 & 37.44 & 9.00 & 18.71 \\
\hline Sodium & 2.10 & 3.30 & 0.90 & 1.95 \\
\hline
\end{tabular}

${ }^{\mathrm{a}}$ Results are mean standard deviation of triplicate determinations

The mineral elements in the agricultural wastes are shown in Table 1.From the table, it is obvious that CPH is more laden with potassium, a precursor for potash formation while OP has the least of $9.00 \%$.The amount of these elements in the by-products is of the order $\mathrm{CPH}>$ $\mathrm{KPH}>\mathrm{PP}>\mathrm{OP}$.

\subsection{Physical and Chemical Characteristics of the Soaps}

Table 2. Physical characteristics of the soaps.

\begin{tabular}{|c|c|c|c|c|c|}
\hline Property & \multicolumn{5}{|c|}{ Value } \\
\hline & CPH & KPH & OP & PP & Standard \\
\hline Appearance & Fine & Fine & Fair & Moderate & Fine \\
\hline Color & Green & $\begin{array}{c}\text { Dark } \\
\text { Green }\end{array}$ & DG & DG & Green \\
\hline Solubility & Good & Good & Good & Good & Excellent \\
\hline Odour & Pleasant & Good & Good & Good & Excellent \\
\hline $\begin{array}{c}\text { Lather } \\
\text { formation }\end{array}$ & V.Good & V.Good & Good & Good & Excellent \\
\hline pH & 9.36 & 8.96 & 9.21 & 9.00 & $9.0-11$ \\
\hline
\end{tabular}

$\mathrm{DG}=$ Dark green

The physical characteristics of the different soaps products are shown in Table 2. It is evident that the appearances of the soaps are fine with the exception of OP that was fair and PP that was moderate in appearance. This difference in appearance may be attributed to the presence of other metallic ions noticeably calcium and magnesium present in OP and PP (Onyegbado et al., 2004). The color, solubility, odour and lather formation of all the soaps were good compared with the standard. The implication of this is that these materials are good starting materials (lye) for the production of soaps. The alkalinity of the soap solutions 
compared favorably with the standard.

Figure 1 shows the free fatty acid of the soaps is all within the acceptable limit for standard soap. Soap produced from kola pod husk had the least free fatty acid of $0.049 \%$ thereby suggesting its mildness in household applications where mildness is a requirement. Figure 2 represents the free alkali of the different soaps produced from the different agricultural materials. The results revealed that while soap produced from PP has high value of $34 \%$ free alkali, that which was obtained from $\mathrm{CPH}$ was $11 \%$ and is lower than the allowable limit. The unsaponifiable neutral fat and the total free fat for KPH derived soap are lower than other derivatives of soap as depicted in figures 3 and 4 . The implication of this is that $\mathrm{KPH}$ derived soap will be better accepted by virtue of its mild nature.

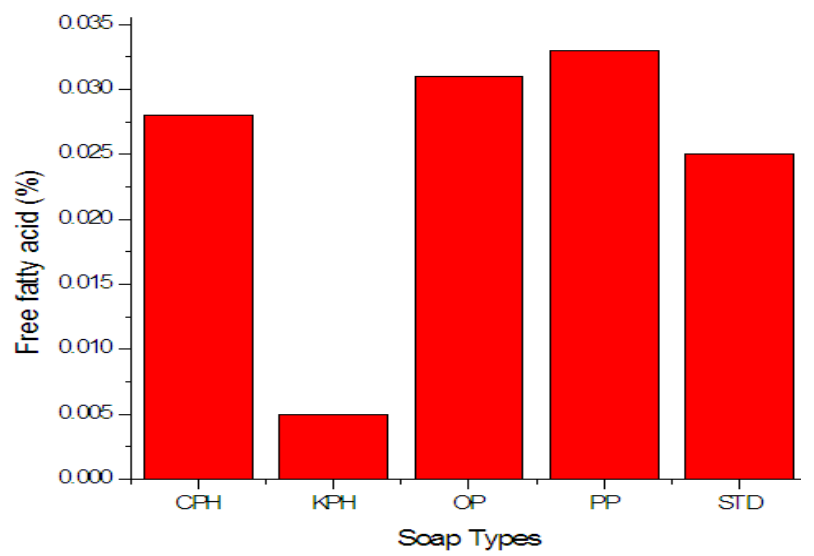

Figure 1. Free fatty acid of the soap variety

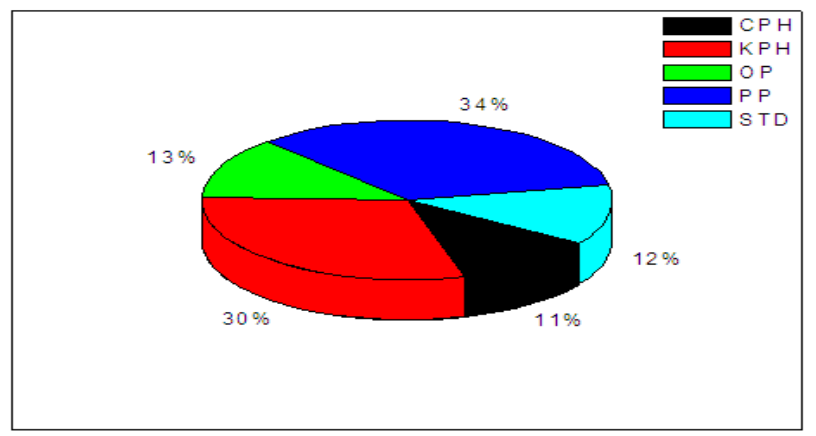

Figure 2. Free alkali $\left(\% \mathrm{~K}_{2} \mathrm{O}\right)$ of the different soap types

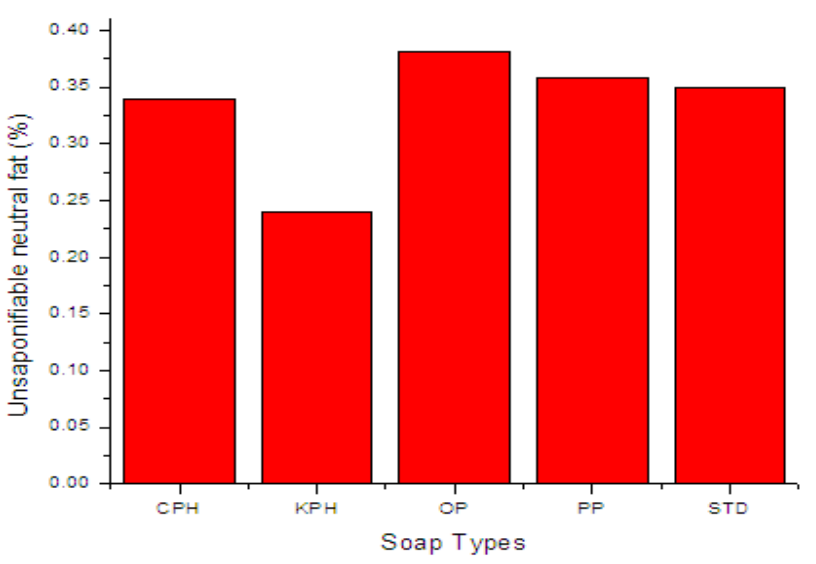

Figure 3. Unsaponifiable neutral fat of the soap variety.

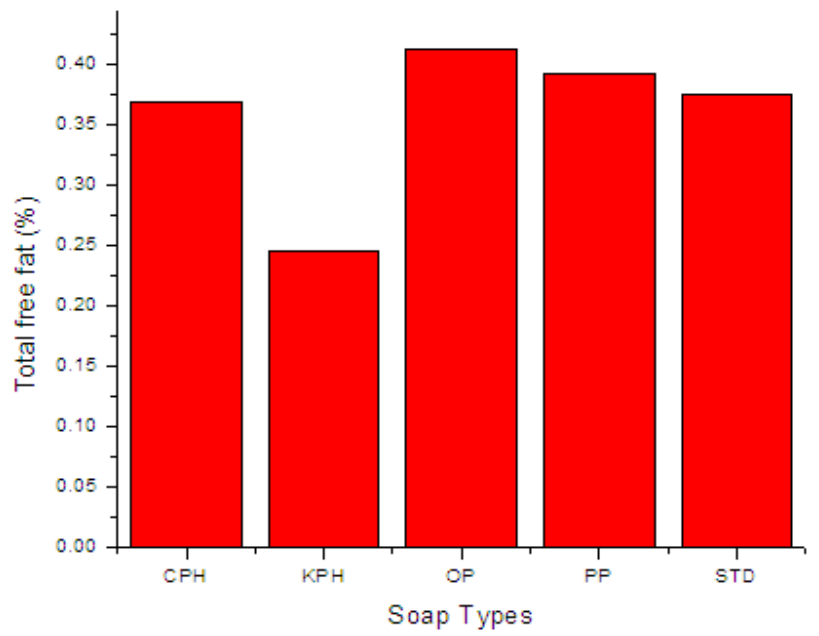

Figure 3. otal free fat of the soap variety.

\section{Conclusions}

From this study, it was clear that most of these agricultural material contains appreciable amount of potash which can be harnessed for surfactant production.

\section{ACKNOWLEDGEMENTS}

The authors wish to thank the laboratory technologists that contributed to this work.

\section{REFERENCES}

[1] AOCS (1965). American Oil Chemist Society, Chicago. Official and Tentative Methods. $3^{\text {rd }} \mathrm{Ed}$

[2] (AOAC). 1990 Official Methods of Analyses, 15 ${ }^{\text {th }}$ Ed. Association of Analytical Chemists. Washington D. C

[3] ASTM (1971). American Society for Testing Materials; Philadelphia, 1971, Annual Books of ASTM standards part 22

[4] CAN (2006). Cocoa Association of Nigeria

[5] Chaco, M.C; Okieimen, F.E and Edema, M.O (1993). Laboratory course in Organic Chemistry. Basic University Chemistry series

[6] Kirk-Othmer (1967). Encyclopedia of Chemical technology, $2^{\text {nd }}$ Ed vol. 1

[7] McCutheon , J.W (1974). In "Detergent and Emulsifier" Annual Report. New Jessey

[8] Onyegbado, C.O, Iyagba, E.T, Offor, O.J (2004). Solid soap production using plantain peels ash as source of alkali. J. Appl. Sci a. Environ. Manage. 6(1)73-77

[9] Shreve, Norris, (1967).Chemical Process technology McGraw Hill, New York

[10] Van Nostrand (1976). Scientific Encyclopedia, Nostrand 
Reinhold Company, New York. 1001

[11] Wilkinson, R N (1974)."Detergents" in chemicals and process technology Encyclopedia. McGraw Hill, New York
[12] Yahaya, L.E; Hamzat, R.A, Aroyeun, S.O and Odufuwa, M.I ,( 2002). Production of liquid detergent from the pod husk of kola (Cola nitida) Moor Journal of Agricultural Research. 3, 253-256 